\title{
Factors influencing the success of root-amputated and restored maxillary molar teeth
}

$\mathrm{PhD}$ Thesis

Balázs Szabó, DDS

Supervisor:

Dr. Márk Fráter, DDS, PhD, M.Sc.
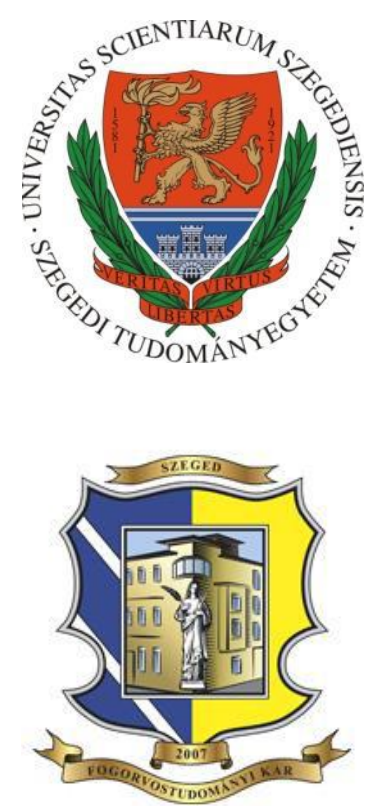

University of Szeged

Faculty of Dentistry

Department of Operative and Esthetic Dentistry

Szeged, Hungary 


\section{Table of Contents}

1. List of the publications providing the basis of and related to the topic of the thesis 4

2. Introduction $\quad 5$

2.1. Indications for root amputation $\quad 6$

2.1.1. Periodontal origin 6

$\begin{array}{ll}\text { 2.1.2. Cariological and endodontic origin } & 7\end{array}$

2.2. Options for restoring root-amputated teeth 8

2.3. Success rate and its aspects in root-amputated teeth 8

3. Materials and Methods 11

3.1.1. Sample selection 11

3.1.2. Cavity preparation and endodontic treatment 11

3.1.3. Coronal restoration 12

3.1.4. Root amputation 15

3.1.5. Embedding the samples and mechanical testing 15

3.2.1. Sample selection 16

3.2.2. Cavity preparation and endodontic treatment 17

$\begin{array}{lr}\text { 3.2.3. Root amputation } & 18\end{array}$

$\begin{array}{lr}\text { 3.2.4. Coronal restoration } & 18\end{array}$

3.2.5. Embedding the samples and mechanical testing 20

4. Results 23

5. Discussion 27

6. Summary 33

7. Acknowledgements 34 
8. References

9. List of abbreviations

10. Appendix 
1. List of the publications providing the basis of and related to the topic of the thesis

\section{Publications providing the basis of the thesis:}

I. Dr. Szabó Balázs, Dr. Eördegh Gabriella, Dr. Szabó P. Balázs, Dr. Fráter Márk. Gyökéramputált és betéttel restaurált felső moláris fogak törési ellenállásának in vitro vizsgálata - Előzetes tanulmány. FOGORVOSI SZEMLE 110. évf. 4. sz. 2017. 111-116.

II. Balázs Szabó, Sufyan Garoushi, Gábor Braunitzer, Balázs Szabó P., Zoltán Baráth \& Márk Fráter. Fracture behavior of root-amputated teeth at different amount of periodontal support - a preliminary in vitro study. BMC Oral Health. 2019 nov $27 ; 19(1): 261$. (IF= 2.08)

III. Balázs Szabó P., Tekla Sáry, Balázs Szabó.The key elements of conducting loadto-fracture mechanical testing on restoration-tooth units in restorative dentistry Analecta Technica Szegedinensia ISSN 2064-7964 Vol 13 No 2 (2019) DOI: 10.14232/analecta.2019.2.59-64 


\section{Introduction}

Periodontitis is considered to be one of the most frequently occurring conditions affecting the health of the teeth and chewing ability in adults; it is regarded as an important health problem (1). Concerning the prevalence of this disease, epidemiological studies report similar results worldwide, though with unique differences (2). In cases of periodontal diseases affecting specialized tissues surrounding and supporting teeth, mostly irreversible deterioration of the alveolar bone occurs. Parallelly with the deterioration of the bone, periodontal ligaments that secure teeth to the bone damage as well; loss of attachment occurs, which can result in the loss of tooth if left untreated (3). The deterioration of the attachment apparatus is a slow process and after a while it can become very diverse in extent and in appearance (4). In multi-rooted teeth, it can create a unique problem called a furcation involvement (5), for which treatment is considered to be one of the most demanding challenges of periodontal interventions. In the treatment of periodontal diseases, conservative and surgical therapies are based on each other (6). The extent and appearance of the disease fundamentally influence the choice of therapy (7). It is generally stated that more extensive defects are rather treated surgically (6). The two main trends of surgical treatment are resective (8) and regenerative (9) periodontal therapy. Resective interventions aim to create a stable, sustainable state based on the current clinical condition by further reduction of the remaining tissues, while regenerative surgical interventions seek to restore the form and function of the original structures. A type of resective surgical intervention is root amputation or root resection. The intervention itself has many names in scientific literature (radisectomy, rhizectomy, odontic trisection, tooth separation, etc.) (10). The indications of root amputations may not only be of periodontal origin, but endodontic and cariological causes are also known (11). Nevertheless, a periodontal origin is more frequent.

According to the definition of the American Academy of Periodontology, root amputation is a surgical intervention in which one or more roots of a multi-rooted tooth is surgically removed at the level of the furcation, while the crown of the tooth and the remaining roots are kept intact (5). And according to Löst's definition: the surgical removal of the root of multi-rooted teeth; during the procedure, only the root or the root and the crown section attached to it is being removed (10). Thus, regarding its implementation, multiple options are available. However, it is more reasonable to separate root amputation from root resection. In case of the former, the root or roots are removed with leaving the crown of the tooth intact. While in case of root 
resection, beside removing the root, a section of the crown of the tooth (attached to the affected root to be removed) is also removed (10). Concerning this topic, special types of resective interventions are trisection, which is the separation of maxillary molar roots, and bicuspidization, which means the separation of mandibular molar roots. A fundamental question is how root amputation influences tooth retention and the life of the tooth, what options are available for restoration after the intervention, and what materials are available for use (12). Also, the aspects that influence the lifetime of teeth that have undergone root amputation and restoration, and the length they may be kept in function are also fundamental questions. As a result of the development and spread of implantology, root amputation has been sent to the background, since it may seem much easier to remove periodontally affected teeth and use dental implants. However, in case of periodontal patients, several unique, problematic issues need to be considered, thus implant therapy needs to be carefully considered in these cases (11, 13). Although, acknowledging the demand from patients to keep their own tooth, more and more teeth are kept that would have been extracted before. This is especially true for periodontal patients, who feel the severity of their conditions, and are more likely to opt for this type of resective periodontal therapy. Thus, root resection remained an effective, durable and wellfunctioning solution besides modern types of periodontal interventions. However, it is important to know its relevant aspects, i.e. survival and lifetime of teeth treated this way $(14,15)$. This thought gave the basis of our research, which manifested in the acquisition of knowledge from scientific literature and empirical studies conducted.

\subsection{Indications of root amputation}

\subsubsection{Periodontal origin:}

With the deterioration of the supporting structures, the bone level around multi-rooted teeth migrate in the apical direction, and the area of root division becomes uncovered. It is called a furcation involvement in scientific literature (5). The name furcation means the division of roots and the periodontal group of tissues surrounded by the roots at the same time. The degree of furcation involvement depends on the extent of bone deterioration and developed patterns. The most commonly used classification that describes the horizontal character of the defect is connected to Hamp $(16,17)$ and was later modified by Ramfjord and Ash (18). The classification described by Tarnow and Fletcher is used for the description of vertical aspects (19). 
The treatment of teeth with furcation involvement is difficult. The anatomical form of teeth and the developed defect poses a challenge to both patients and periodontists carrying out professional oral hygiene; sometimes it creates an area that is not cleanable. The area is simply poorly accessible and with the deterioration of its status, plaque retentive factors increase (20). Results of regenerative surgery are highly uncertain in these cases; mostly lighter degrees of horizontal involvement promise more favorable results (21). Most periodontal indications consist of cases with furcation involvement.

\section{Indications:}

- Grade II and III furcation involvement

- An extensive bone loss of endodontic and periodontal origin affecting the root

- Severe dehiscence and recession

- Proximity of the root of an adjacent tooth, and the combination of the previously listed factors

\subsubsection{Cariological and endodontic origin:}

Most of the time, these cases are not attributed to the insufficient quantity of the periodontal tissues but to the failure of the root canal treatment (10). Cariological origins may be such cases of hard tissue loss, where the removal of caries would make the restoration of the tooth questionable. In these cases, root amputation can only be an option, if any other choice of therapy would not be feasible or successful (22).

\section{Indications:}

Endodontic:

- Non-feasible proper root canal treatment and/or filling:

- The root canal is undiscoverable/inaccessible

- Perforation occurring during accessing or the chemo-mechanical preparation of the root canal, which cannot be treated otherwise

- Fracture of an endodontic instrument, which cannot be treated otherwise

- External and internal resorptions, which cannot be treated otherwise 
- Crack and/or fracture

Cariology, restorative:

- Weakened, caries-affected furcation area

- Errors occurring during placing the post (fracture or perforation)

- Root caries

\subsection{Options for restoring root-amputated teeth}

Restorations fundamentally depends on the type of the resective intervention. In cases of classical root amputations not affecting the crown of the tooth, the restoration of the crown basically depends on the original cariological state of the tooth; endodontic interventions necessary to the root amputation will modify this. In cases when there is no extensive loss of dental substance, it is enough to restore the crown in compliance with modern restorative guidelines with the use of minimally invasive techniques. This is mostly a direct or indirect restoration, from which the latter is based on restorative materials placed adhesively. In cases where root resection is used, it is absolutely necessary to have the tooth restored with a fullcoverage crown (10) or a dental bridge, since the surgical intervention affected the crown as well. An important aspect is the substitution of the area between the restoration and the residual dental substance. In order to strengthen the tooth, the use of a root canal post or a short fibrereinforced composite as a material for core build-up, or other unidirectional or bidirectional glass fibre-reinforced or polyethylene materials may be used for this purpose.

\subsection{Success rate and its aspects in root-amputated teeth}

Root amputation has been a possible therapeutic method for treating furcation involvement for more than a hundred years (10). The prognosis of the affected teeth is well documented in scientific literature, but the survival rate shows huge differences (14). The reason for this difference may lie in the differences in the parameters of teeth, the nature of the intervention, the type of restoration, the unique aspects of periodontal baseline conditions, oral hygiene factors of patients, habitual factors and several other factors presented in these studies (14). 
Lack of success, in this sense, obviously means the loss of the restored tooth that underwent root amputation, most likely by extraction. In a study, Hamp et al. (24) discussed that the factors modifying the success rate of root-amputated teeth are the following: dominantly the rate of the periodontal attachment (25), anatomy of the pulp chamber and the roots, periapical status and the intermaxillary relations (type of restoration, amount of occlusal loading). According to Langer et al., the success rate of root-amputated teeth should be evaluated after at least 10 years of follow-up time in in vivo studies (26). An important factor is the contact point system for teeth in order to retain stability; obviously, this is true also for teeth not affected periodontally, but it is especially valid in cases of reduced periodontium. The question of a potential splinting arises, which is basically related to the degree of mobility and its progression. Scientific data indicates that the mobility of maxillary teeth is not necessarily increased solely by root amputation itself (27). The fracture of periodontally compromised teeth is one of the most common reasons for failure in case of maxillary teeth. In a 10-year follow-up study, Carnevale et al. evaluated the survival rate of root-resected teeth in 72 patients, which was $93 \%$. Loss of teeth mostly occurred between the fifth and the seventh year (28). In a 10-year retrospective study, Park et al. analysed 691 root-resected teeth of 579 patients. During this period, the success rate was $70.2 \%$ (22). They defined non-success according to the principles laid out by Langer in $1981(22,26)$. They expressed that the bone support of the retained roots must be at least $50 \%$ of the original for predictable results. From the teeth evaluated in this study, maxillary molar teeth became non-retainable due to the further deterioration of periodontal tissues, while in case of mandibular teeth it was due to fracture. In 2012, Lee et al. examined the 10-year follow-up of molar teeth treated this way and it resulted in a $40.3 \%$ of success. They regarded age, preoperative bone volume around the residual root, preoperative mobility and splinting as the most dominant factors of failure (29).

\section{Factors influencing success/failure $(14,15)$ :}

- Baseline periodontal condition, bone support

- Progression of periodontitis

- Emergence of acute processes

- Tooth, anatomical characteristics of roots (root length, root curvature, surface and dimensions of the root trunk, crossection of the root) 
- Success of endodontic treatment, baseline periapical condition

- Restorative techniques and materials, change of crown-to-root ratio

- Splinting, the aspect of contact point system

- Oral hygiene and motivation of the patient, habitual factors, genetic background, success of periodontal supportive therapy

\section{The most common manifestations of failure $(14,15,23)$ :}

- Periapical disorders: cyst, abscess, resorption

- Deterioration of periodontal tissues, mobility increase over the level of retention

- Fracture of teeth and/or restorations that cannot be reconstructed

- Secondary, non-restorable caries

Based on these, it is visible that with proper (lege artis) pre-treatment and appropriate patient cooperation, the following factors are the ones mostly influencing the success rate: quantity of residual periodontal tissues, type of crown restoration and type and distribution of tooth loading.

The aim of our investigations:

Thus, our aim was to in vitro examine the behaviour of root-amputated maxillary molar teeth in situations of static loading. To determine how the amount of remaining alveolar bone affects the resistance against static loading, and what role does the dental restoration play in the fracture resistance outcome. In the studies, we examined maxillary first molars, since in contrast to mandibular molar teeth, classic root amputation is an indicated approach. Concerning mandibular molar teeth, dissection is the similar, recommended type of periodontal intervention.

The null hypotheses were the following: 1. there would be no difference in the maximal fracture resistance between the tested groups with different alveolar bone levels . 2. there would be no difference in fracture pattern between the tested groups with different alveolar bone levels. 
This thesis is based on two investigations, a pilot study of which the conclusions were used two years later as the basis of the other more extended second study.

\section{Materials and Methods}

\subsubsection{Sample selection}

All procedures of the study were approved by the Ethics Committee of the University of Szeged, and the study was designed in accordance with the Declaration of Helsinki.

In the pilot study 40 maxillary molars and 20 maxillary premolars extracted for periodontal or orthodontic reasons were selected for this study. The teeth were collected from patients of the University of Szeged Faculty of Dentistry. The freshly extracted teeth were immediately placed in $5.25 \% \mathrm{NaOCl}$ for 5 minutes and then stored in $0.9 \%$ saline solution at room temperature until the soft tissues from the root surface were removed with hand scalers. All teeth were used within 6 months after extraction. The first inclusion criteria were visual absence of caries or root cracks, absence of previous endodontic treatment, posts or crown or resorptions. Teeth with severe polymorphism of the coronal structures were excluded from the investigation. About eighty percent of the specimens ranged 8.0 to $9.0 \mathrm{~mm}$ in size, measured at the widest buccopalatinal dimension, and the rest were between 9.0 and $10.0 \mathrm{~mm}$. The mesio-distal dimension of the specimens was also measured, and this parameter allowed a maximum deviation of $10 \%$ from the determined mean. Also, root length was standardized as follows: mesio-buccal: 11.5$13 \mathrm{~mm}$, disto-buccal: $11.5-13 \mathrm{~mm}$, palatal 12.5-14.5 mm. Based on these criteria, fourteen maxillary first molars were selected. The rest of the molar and premolar teeth were set aside to be used during the embedding procedure (see later).

\subsubsection{Cavity preparation and endodontic treatment}

Teeth were distributed into 2 groups (Group 1 and 2, n=7). All procedures were performed by the same trained operator. Standardized mesio-occluso-distal (MOD) cavities were prepared according to Cara et al. (30) in both groups. The bucco-palatinal width (BPW) of the approximal box of each cavity was two-thirds of the BPW of the tooth, and the occlusal isthmus was half the BPW. In addition, the cavity depth at the occlusal isthmus was standardized to $3.5 \mathrm{~mm}$ from the tip of the palatinal cusp and $1 \mathrm{~mm}$ above the cemento-enamel junction (CEJ) at the cervical aspect of the approximal boxes (Figure 1). 


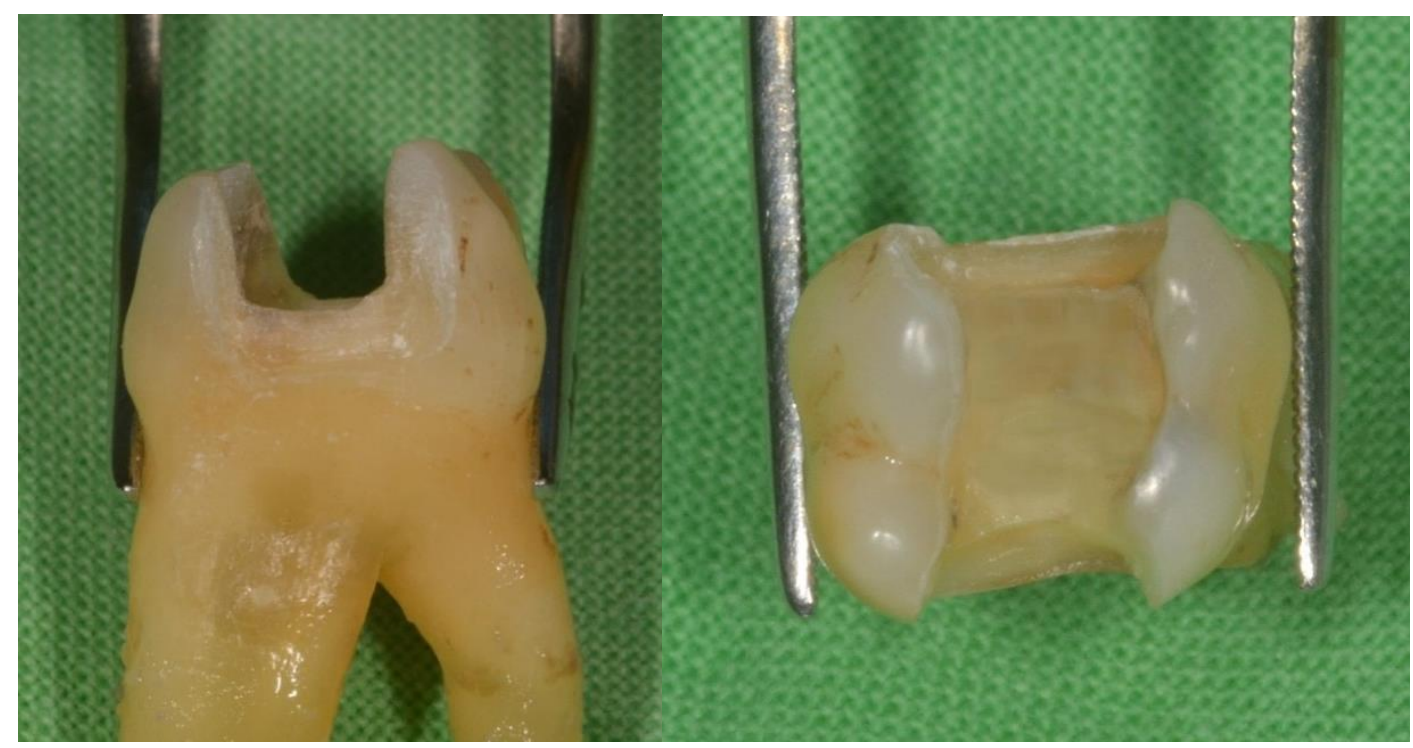

Figure 1. Images showing the prepared cavity and its dimensions according to parameters given by Cara et al. (30).

After cavity preparation, the roof of the pulp chamber was removed, and root canal treatment was initiated. The root canals were preflared with No 2-3-4 Gates Glidden burs and instrumented with Pathfiles (1-2-3) and ProTaper (S1-S2-F1-F2-F3) (Dentsply Maillefer) to the working length. The specimens were irrigated with $5 \% \mathrm{NaOCl}$ with a $2-\mathrm{mL}$ syringe and $25-$ gauge needle. Root canal filling was performed by matched-single-cone obturation with a master cone (F3 gutta-percha, Dentsply-Maillefer) matching the final instrument used for preparation and sealer (AH plus; Dentsply De Trey GmbH, Konstanz, Germany). Following root canal obturation, the root canal filling was cut back $2 \mathrm{~mm}$ under the orifices and a base was applied to the pulp chamber in the form of an approx. 2-3 $\mathrm{mm}$ thick glass-ionomer barrier (Equia Forte, GC Europe, Leuven, Belgium).

\subsubsection{Coronal restoration}

As the base lining set, the cavity preparation was finalized. The cavosurface margins were prepared perpendicular to the tooth surface at the end of the preparation. The cavity was rinsed with water and air-dried with an air/water syringe. All prepared specimens received the same adhesive treatment. The enamel was acid-etched selectively with $37 \%$ phosphoric acid for 15 seconds, rinsed with water and air-dried. The cavity was adhesive-treated with G-Premio Bond (GC Europe, Leuven, Belgium) according to the manufacturer's instructions. The adhesive layer was light-cured for $40 \mathrm{~s}$ with an Optilux 501 halogen light (Kerr, Orange, CA, USA) 
operating in standard mode at a light intensity of $740+/-36 \mathrm{mWcm}^{2}$. In all groups, an approximately 0.5 mm-thick flow composite layer (G-aenial Flo, GC Europe, Leuven, Belgium) was applied on the floor of the cavity. This layer was light-cured for $40 \mathrm{~s}$. After applying the flowable layer, the missing dentine was rebuilt from short fiber-reinforced composite (SFRC, everX Posterior, GC Europe, Leuven, Belgium). The core material was placed in 2 increments according to the anatomy of the dentine, leaving approx. $2 \mathrm{~mm}$ occlusally for the final composite direct or indirect restoration as prescribed by the manufacturer. Each increment was light-cured from the occlusal surface for 40 seconds.

Finally, all cusps were reduced by $2 \mathrm{~mm}$ of their original height and the cavity margins were refined. Polyether impression (Permadyne, 3M ESPE) was taken of each prepared specimen, using a simultaneous mixing technique according to the manufacturer's instructions. Provisional restorations were fabricated with Fermit N (Ivoclar Vivadent, Schaan, Lichtenstein), adapted to the cavity, and light- polymerized without interim cement placement. The impressions were molded and composite resin overlays (Gradia Lab, GC Europe, Leuven, Belgium) were prepared by the same technician for each prepared molar specimen. Special attention was paid that the overlay between $2-2.2 \mathrm{~mm}$ thickness at every point: after the fabrication of the overlay, the thickness was checked with a digital caliper (Mitutoyo Corp., Kawasaki, Japan) at 9 different points, and occlusal reduction was carried out wherever necessary to have the desired thickness (Figure 2 and 3). 


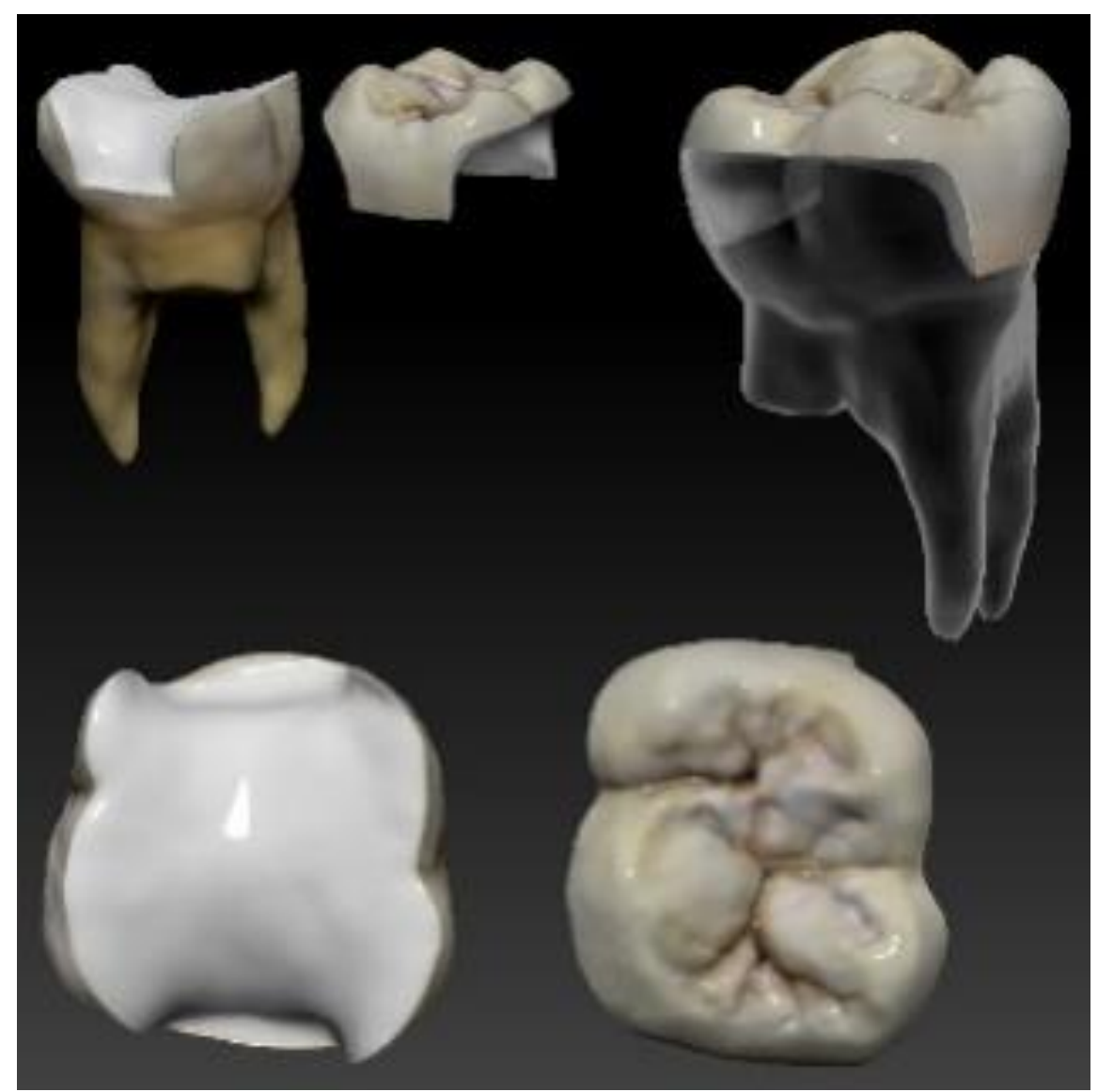

Figure 2. Schematic picture showing the design of the overlay.
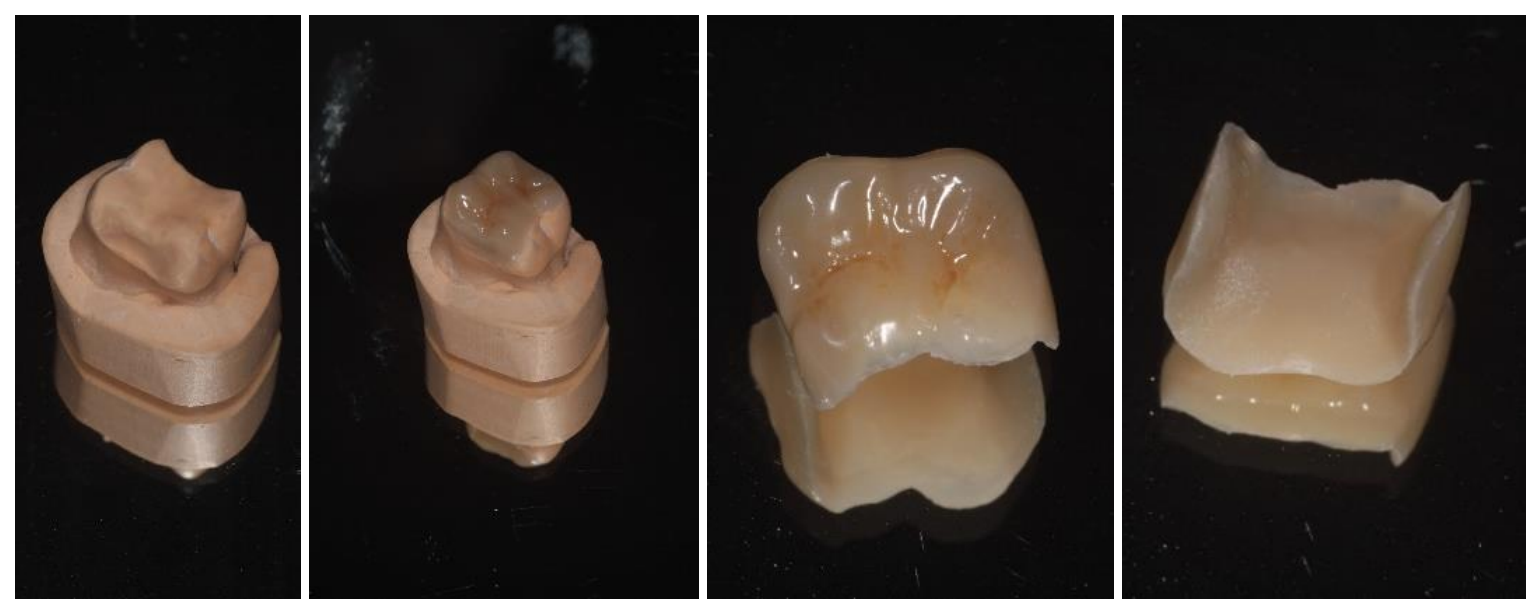

Figure 3. Photos of the design of the composite overlay.

At the luting the intaglio surface of the composite overlays was sandblasted, rinsed and ultrasonically cleaned (Emag, Valkenswaard, Netherlands) in distilled water in 5 minutes. They were then silanized (Ceramic Primer, GC Europe, Leuven, Belgium) and heat dried for $1 \mathrm{~min}$ at $100{ }^{\circ} \mathrm{C}$ (DI500, Coltene, Altstatten, Switzerland) and coated with a thin layer of adhesive 
resin (Stick Resin, GC Europe, Leuven, Belgium). Regarding the prepared tooth, the enamel margins were etched with $37 \%$ phosphoric acid for 30 seconds, rinsed with water and air-dried. Then the adhesive resin (Stick Resin, GC Europe, Leuven, Belgium) was applied and airthinned, but not photopolymerized. The overlays were luted with pre-heated restorative composite resin (Gradia Anterior A2, GC Europe, Leuven, Belgium). The luting agent was applied onto the intaglio surface of the overlays and applied on the teeth under finger pressure until complete adaptation. After removing the excess material, glycerine gel (DeOx Gel, Ultradent Products Inc., Orange, CA, USA) was applied and photopolymerization from each side for 40 seconds with Optilux 501 was performed.

\subsubsection{Root amputation}

Each mesio-buccal (MB) root was sectioned horizontally at the level of the furcation with a fissure diamond bur (881.31.014 FG - Brasseler USA Dental, Savannah, GA). The sectioned surfaces were smoothened to eliminate any remnants below the sectioning level in order to have a cleansable non-retentive surface. The cut surface was not covered with anything as it should be in the clinical practice because it was irrelevant.

\subsubsection{Embedding the samples and mechanical testing}

The restored specimens were stored in physiological saline solution (Isotonic Saline Solution 0.9\%; B. Braun, Melsungen, Germany) in an incubator (mco-18aic; Sanyo, Moriguchi, Japan) at $37^{\circ} \mathrm{C}$. Molars and premolars not selected for restoration were used as neighboring teeth to produce a tight interproximal contact on both sides. To simulate the periodontal ligament, the root surface of each tooth was coated with a layer of liquid latex separating material (RubberSep, Kerr, Orange, CA) prior to embedding. Three-teeth units were formed with the restored specimen always in the middle. Specimens in Group 1 were embedded in methacrylate resin (Technovit 4004, Heraeus-Kulzer) at $2 \mathrm{~mm}$ from the CEJ to simulate the normal bone level, while specimens in Group 2 were embedded 3.5-4.5 mm from the CEJ at the level of the furcation to simulate a grade I. furcation involvement. All specimens were quasi-statically loaded with a crosshead speed of $2 \mathrm{~mm} / \mathrm{min}$ parallel to the long axis of the tooth in an universal testing machine (Lloyd 1000R, Lloyd instruments Ltd, Fareham, UK) until they fractured. A $10 \mathrm{~mm}$ long and $6 \mathrm{~mm}$ in diameter cylindrical steel bar was used (31,32). The bar was positioned 
at the center of the occlusal surface of the crown between the buccal and palatal cusps. A force vs. time curve was dynamically plotted for each tooth. The failure load of the specimen was defined as the load when the force versus time graph showed an abrupt change, indicating a sudden decrease in the specimen's resistance to compressive loading. Specimens were visually examined for the type and location, as well as direction of failure. According to Scotti and coworkers, distinction was made between restorable or non-restorable fractures (under optical microscope with a two-examiner agreement). A restorable fracture is above the CEJ, meaning that in case of fracture, the tooth can be restored, while a nonrestorable fracture extends below the CEJ and extraction is indicated (33) (Figure 4).

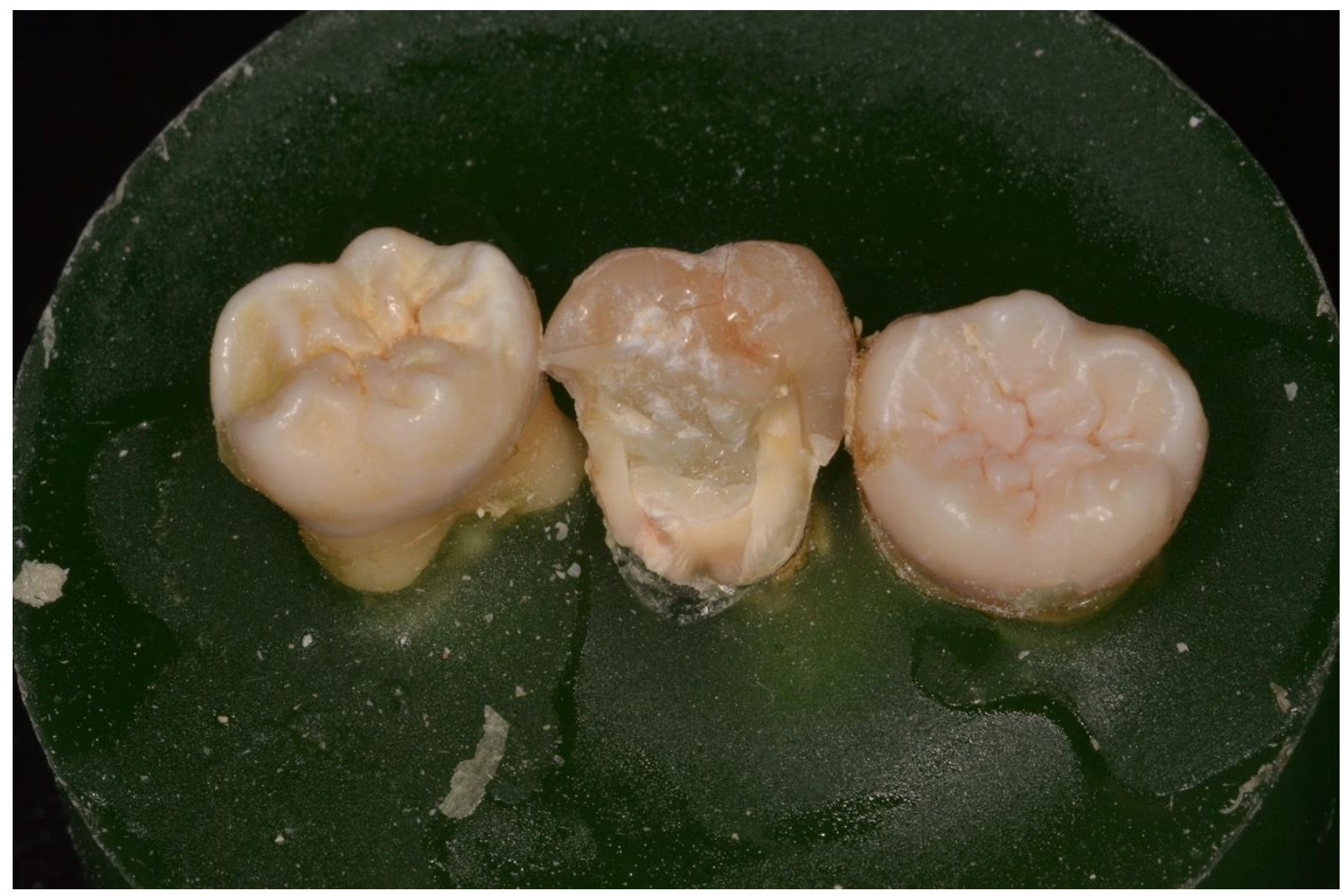

Figure 4. An example of the three-teeth units showing a nonrestorable fracture after mechanical testing.

\subsubsection{Sample selection}

In the second study 180 maxillary molars and 80 maxillary premolars extracted for periodontal or orthodontic reasons were selected. The first inclusion criteria was the same as in the pilot study. Again, teeth with severe polymorphism of the coronal structures were excluded from the investigation. In this study about eighty percent of the specimens ranged 10.0 to $10.9 \mathrm{~mm}$ in 
size, measured at the widest bucco-palatinal dimension, and the rest were between 11.0 and $12.0 \mathrm{~mm}$. The mesio-distal dimension of the specimens was also measured, and this parameter allowed a maximum deviation of $10 \%$ from the determined mean. Also, root length was standardized as follows: mesio-buccal: $12-14 \mathrm{~mm}$, disto-buccal: 11-13 mm, palatal 12-15 mm. Based on these criteria, sixty maxillary first molars were selected. The rest of the molar and premolar teeth were set aside to be used during the embedding procedure (as described in the pilot study).

\subsubsection{Cavity preparation and endodontic treatment}

Teeth were distributed into four groups (Group 3-6, n=15). All procedures were performed by the same trained operator. In Group 3 and 4 standardized MOD cavities were prepared according to Cara et al. (30) as described earlier. After cavity preparation, the roof of the pulp chamber was removed, and root canal treatment was initiated. Teeth in Groups 5 and 6 received

a Class I. cavity preparation which was continued into a traditional endodontic access (TEC) following the principles of TECs as previously reported (34,35) (Figure 5).

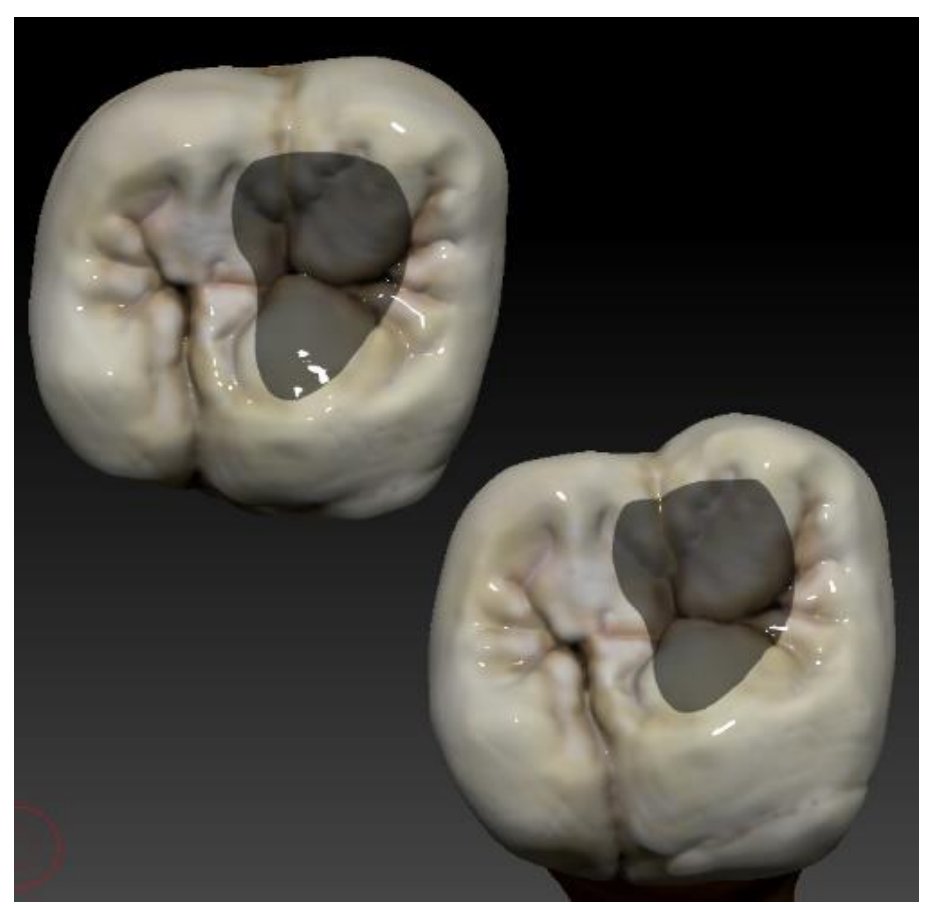

Figure 5. Schematic picture showing the design of the traditional endodontic access (TEC) used in our study. 
Endodontic treatment was performed in all specimen with the same method described in the pilot study. Following root canal obturation, the root canal filling was cut back $2 \mathrm{~mm}$ under the orifices and a base was applied to the pulp chamber in the form of an approx. 2-3 mm thick resin-modified glass-ionomer barrier (Fuji II LC, GC Europe, Leuven, Belgium).

\subsubsection{Root amputation}

As the base lining set, each mesio-buccal (MB) root was sectioned horizontally at the level of the furcation with a fissure diamond bur (881.31.014 FG - Brasseler USA Dental, Savannah, GA). The sectioned surfaces were smoothened to eliminate any remnants below the sectioning level in order to have a cleansable non-retentive surface (Figure 6).

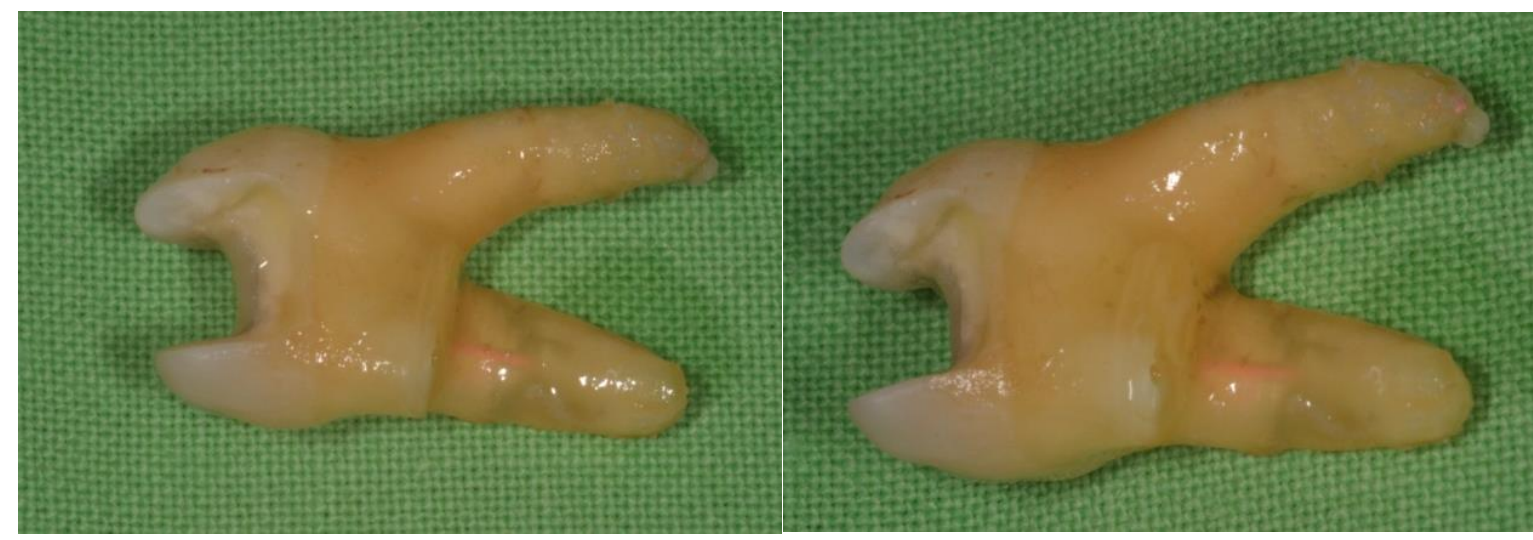

Figure 6. Photos of the samples showing the amputated area.

\subsubsection{Coronal restoration}

The cavosurface margins were prepared perpendicular to the tooth surface at the end of the preparation. The cavity was rinsed with water and air-dried with an air/water syringe. All prepared specimens received the same adhesive treatment and core build-up from SFRC as in the pilot study.

In Groups 5 and 6, the last occlusal layer was composite material (Gradia Direct Posterior A2, GC Europe, Leuven, Belgium) covering the SFRC. Glycerine gel (DeOx Gel, Ultradent Products Inc., Orange, CA, USA) was applied and final polymerization from each side for $40 \mathrm{~s}$ with Optilux 501 was performed (Figure 7). 
In Groups 3 and 4, all cusps were reduced by $2 \mathrm{~mm}$ of their original height and the cavities were restored with indirect composite overlays (Figure 8) as described in the pilot study. The fabrication of the overlays and the luting of them was the same in both research.

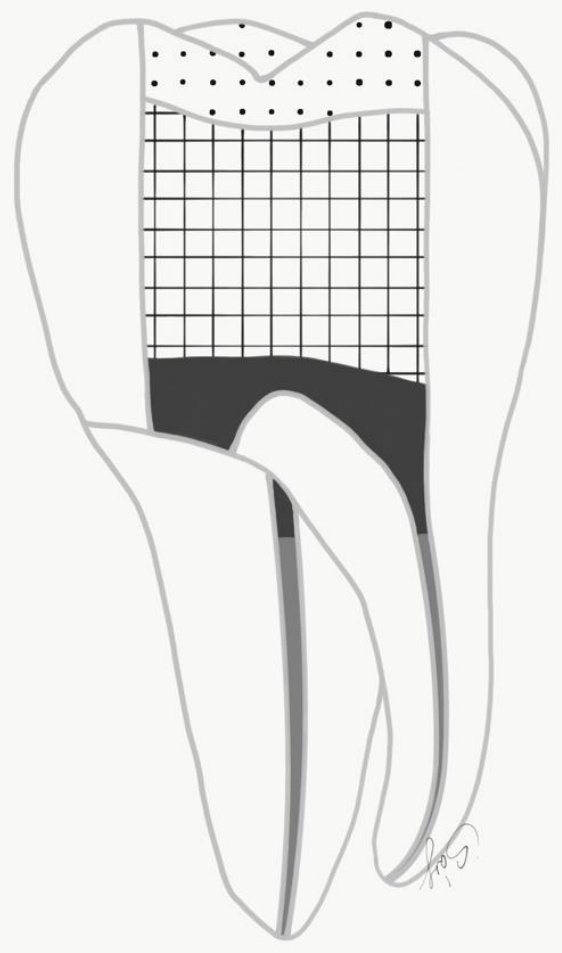

Figure 7. Schematic figure representing the groups (Group 5 and 6) restored with the direct filling. 


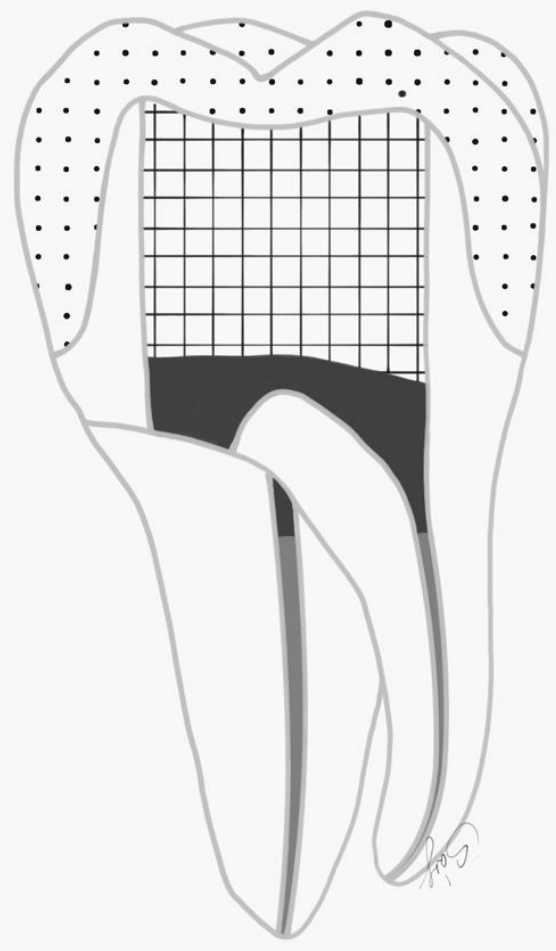

Figure 8. Schematic figure representing the groups (Group 1 and 2 in the pilot study, and Group 3 and 4 in the second study) restored with the indirect overlay.

\subsubsection{Embedding the samples and mechanical testing}

Molars and premolars not selected for restoration were used as neighboring teeth to produce a tight interproximal contact on both sides. To simulate the periodontal ligament, the root surface of each tooth was coated with a layer of liquid latex separating material (Rubber-Sep, Kerr, Orange, CA) prior to embedding. Three- teeth units were formed with the restored specimen always in the middle. Specimens in Group 3 and 5 were embedded in methacrylate resin (Technovit 4004, Heraeus-Kulzer) at $2 \mathrm{~mm}$ from the CEJ to simulate the normal bone level (Figure 9), while specimens in Group 4 and 6 were embedded 3.5-4.5 $\mathrm{mm}$ from the CEJ at the level of the furcation to simulate a grade I. furcation involvement (Figure 10). Mechanical testing was performed exactly according to the same parameters as in the pilot study. Evaluation of the fractured samples was made according to Scotti et al. (33). 

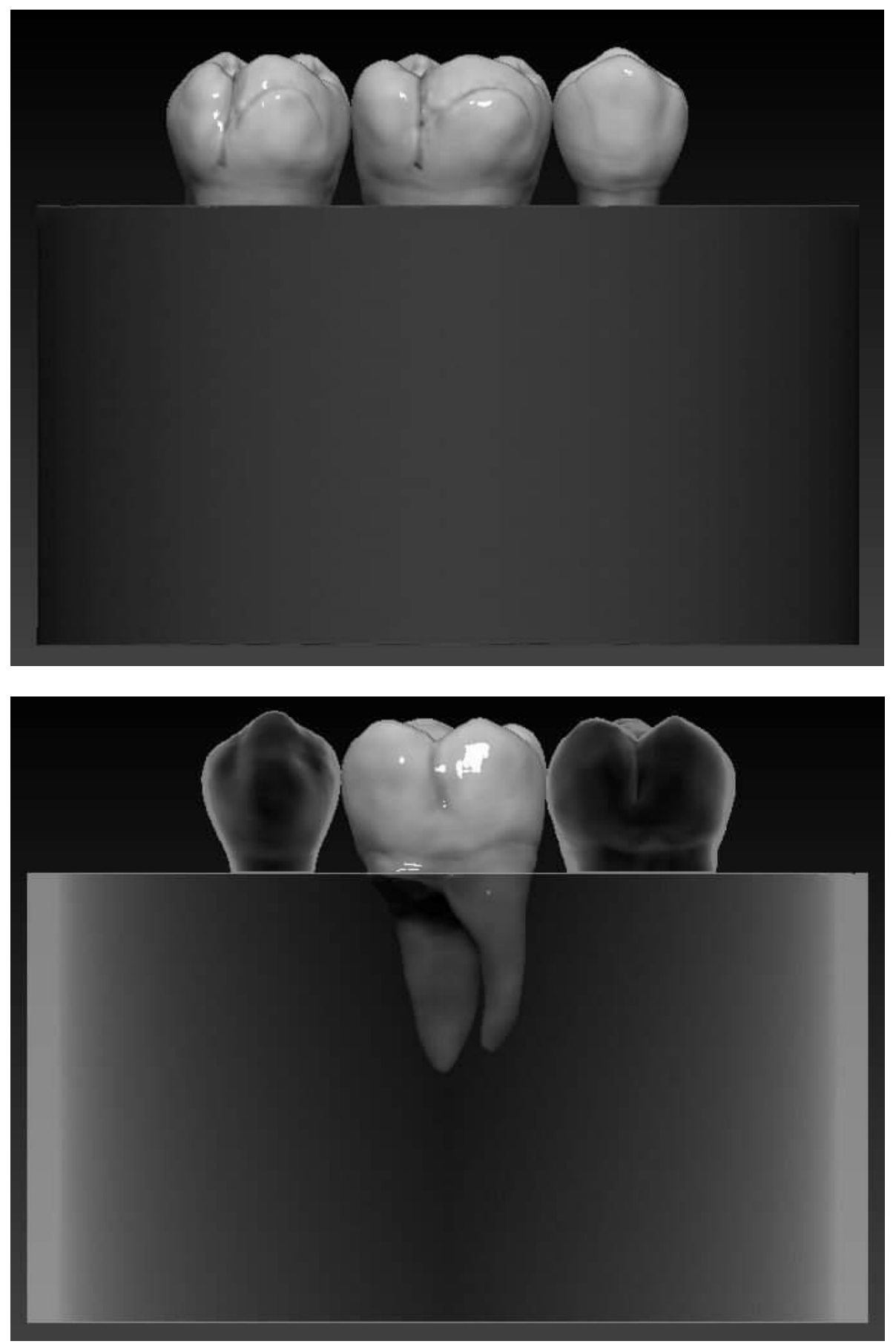

Figure 9. Schematic figures representing the groups (Group 1 in the pilot study, and Group 3 and 5 in the second study) with a simulated normal bone level. 

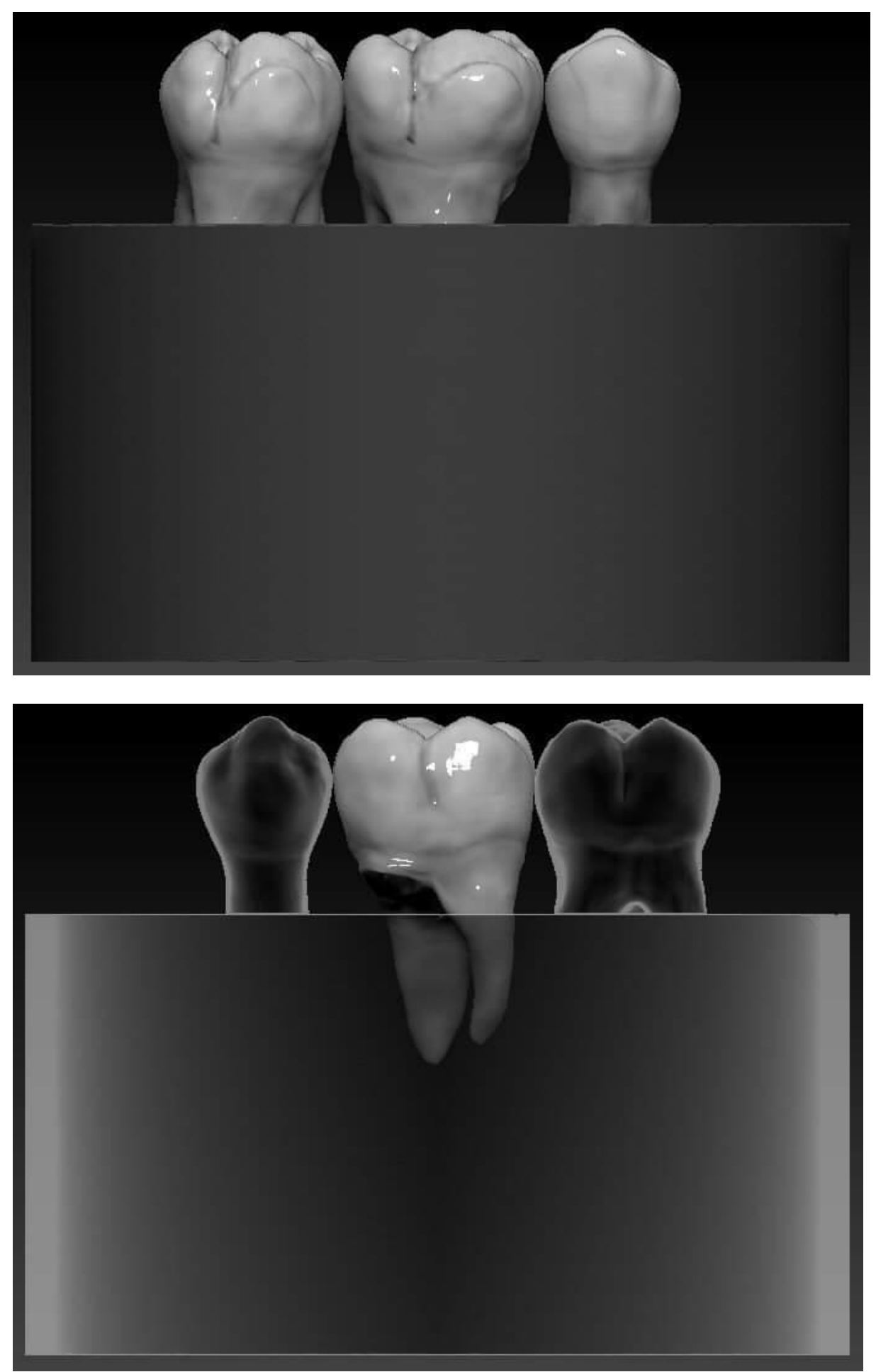

Figure 10. Schematic figures representing the groups (Group 2 in the pilot study, and Group 4 and 6 in the second study) with a simulated Grade I. furcation involvement. 
Statistical analysis was conducted in SPSS 23.0 (SPSS Inc., Chicago, IL). For the comparisons between the groups (Group 3-6), ANOVA with Tukey's HSD post-hoc test was used. The general limit of significance was set at $\alpha=0.05$.

\section{Results}

Figure 11. shows the fracture resistance and associated standard deviation for the 2 study groups in the pilot study. In the pilot study the fracture resistance of root amputated teeth with sound periodontal support (Group 1) yielded higher fracture resistance $($ mean $=2655.53 \mathrm{~N}, \mathrm{SD}=$ $\pm 1107.27 \mathrm{~N}, \mathrm{n}=7$ ) than the ones with damaged periodontal support (Group 2) (mean $=1624,12$ $\mathrm{N}, \mathrm{SD}= \pm 535.03 \mathrm{~N}, \mathrm{n}=7$ ). This difference is 1.6 fold, however, due to the small amount of samples statistical analysis could not be carried out.

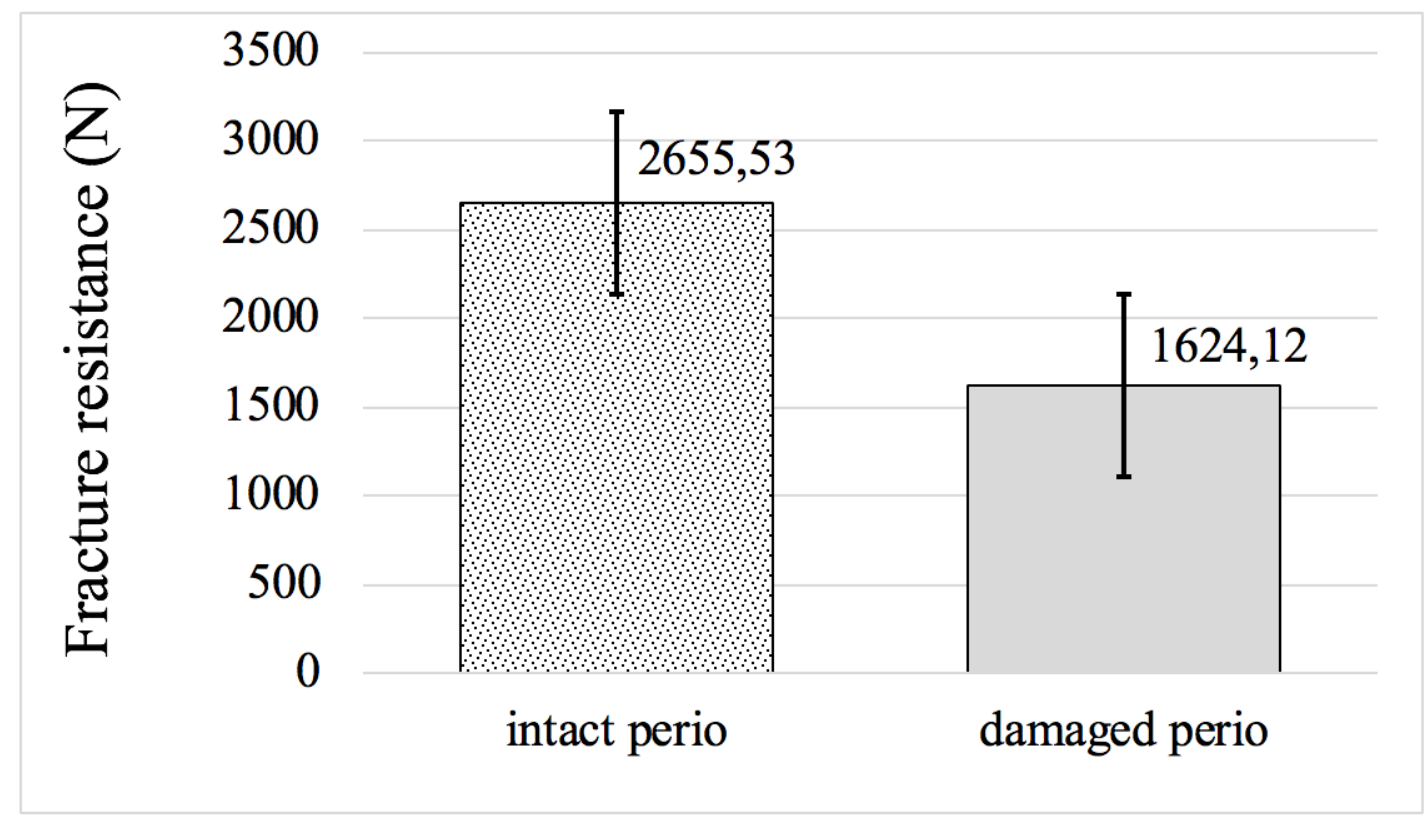

Figure 11. Fracture resistance values and related standard deviation for Group 1 and 2 in the pilot study. The bar chart nicely shows the difference in case of different periodontal support, in spite of the fact that due to small sample size statistical analysis should not be carried out. 
Regarding the fracture pattern of the pilot groups all the samples in Group 2 exhibited unfavorable fractures, whereas the ratio of favorable and unfavorable was approximately the same in the group with sound periodontal support (Group 1) (Table 1).

\begin{tabular}{|c|c|c|}
\hline $\begin{array}{c}\text { Fracture } \\
\text { pattern }\end{array}$ & Gr1 & Gr2 \\
\hline favorable & $4(57,14 \%)$ & $0(0 \%)$ \\
\hline unfavorable & $3(42,85 \%)$ & $7(100 \%)$ \\
\hline
\end{tabular}

Table 1. Fracture patterns by group. Numbers of observations and within-group percentages.

Table 2. summarizes the fracture thresholds for the different study groups (Group 3-6) in the second research. Groups without furcation involvement exhibited higher fracture resistance than groups with furcation involvement. Teeth restored with an indirect overlay with normal periodontal support (Group 3) yielded the highest fracture resistance $(2311.6 \mathrm{~N})$ among the restored groups and showed statistically significant difference compared to Group 4 ( $p=0.038)$ and Group $6(p=0.0011)$. Therefore, the null hypothesis regarding fracture resistance was rejected in the second study. There was no statistically significant difference in terms of fracture resistance between the rest of the groups. The results of the post-hoc pairwise comparisons (Tukey's HSD) are given in Table 3.

\begin{tabular}{|l|l|l|l|l|l|}
\hline Group & N & Mean & Minimum & Maximum & SD \\
\hline Gr 3 & 15 & 2311.60 & 811.00 & 3858.00 & 894.78 \\
\hline Gr 4 & 15 & 1682.73 & 739.00 & 2502.00 & 428.64 \\
\hline Gr 5 & 15 & 1844.93 & 1059.00 & 3517.00 & 650.22 \\
\hline Gr 6 & 15 & 1397.33 & 686.00 & 2212.00 & 395.74 \\
\hline
\end{tabular}

Table 2. Fracture resistance values and related descriptive statistics in the tested groups. Mean values were given in Newtons. Groups: 3- no furcation involvement, indirect overlay; 4- furcation involvement, indirect overlay; 5- no furcation involvement, direct restoration; 6- furcation involvement, direct restoration. 


\begin{tabular}{|c|c|c|c|c|}
\hline Group & Gr3 & Gr4 & Gr5 & Gr6 \\
\hline Gr 3 & & 0.038596 & 0.184543 & 0.001153 \\
\hline Gr 4 & 0.038596 & & 0.892625 & 0.598182 \\
\hline Gr 5 & 0.184543 & 0.892625 & & 0.215362 \\
\hline Gr 6 & 0.001153 & 0.598182 & 0.215362 & \\
\hline
\end{tabular}

Table 3. Significance matrix from the post-hoc pairwise comparisons (Tukey's HSD, pvalues). The conventions are the same as in Table 2. Significant differences are highlighted in red.

In terms of the fracture patterns (Table 4), Group 5 was characterized by the highest percentage of favorable (i.e. reparable) fractures, while the rest of the groups showed dominantly unfavorable fractures. Therefore, the null hypothesis regarding fracture patterns was also rejected in the second study.

\begin{tabular}{|c|c|c|c|c|}
\hline $\begin{array}{c}\text { Fracture } \\
\text { pattern }\end{array}$ & Gr3 & Gr4 & Gr5 & Gr6 \\
\hline favorable & $6(40 \%)$ & $2(13 \%)$ & $9(60 \%)$ & $5(33 \%)$ \\
\hline unfavorable & $9(60 \%)$ & $13(87 \%)$ & $6(40 \%)$ & $10(67 \%)$ \\
\hline
\end{tabular}

Table 4. Fracture patterns by group. Numbers of observations and within-group percentages. The conventions are the same as in Table 1.

In the second study factorial ANOVA was conducted to determine the individual contributions of the two examined factors (types of restoration and bone level) to the variability of fracture resistance. The results indicate that both bone level $(p=0.002)$ and the type of restoration $(p=0.023)$ contribute significantly to the observed differences, while their effects are independent $(p=0.58)$. A graphical summary of the findings is given in Figure 12. Descriptive statistics are presented in Tables 5 and 6. 


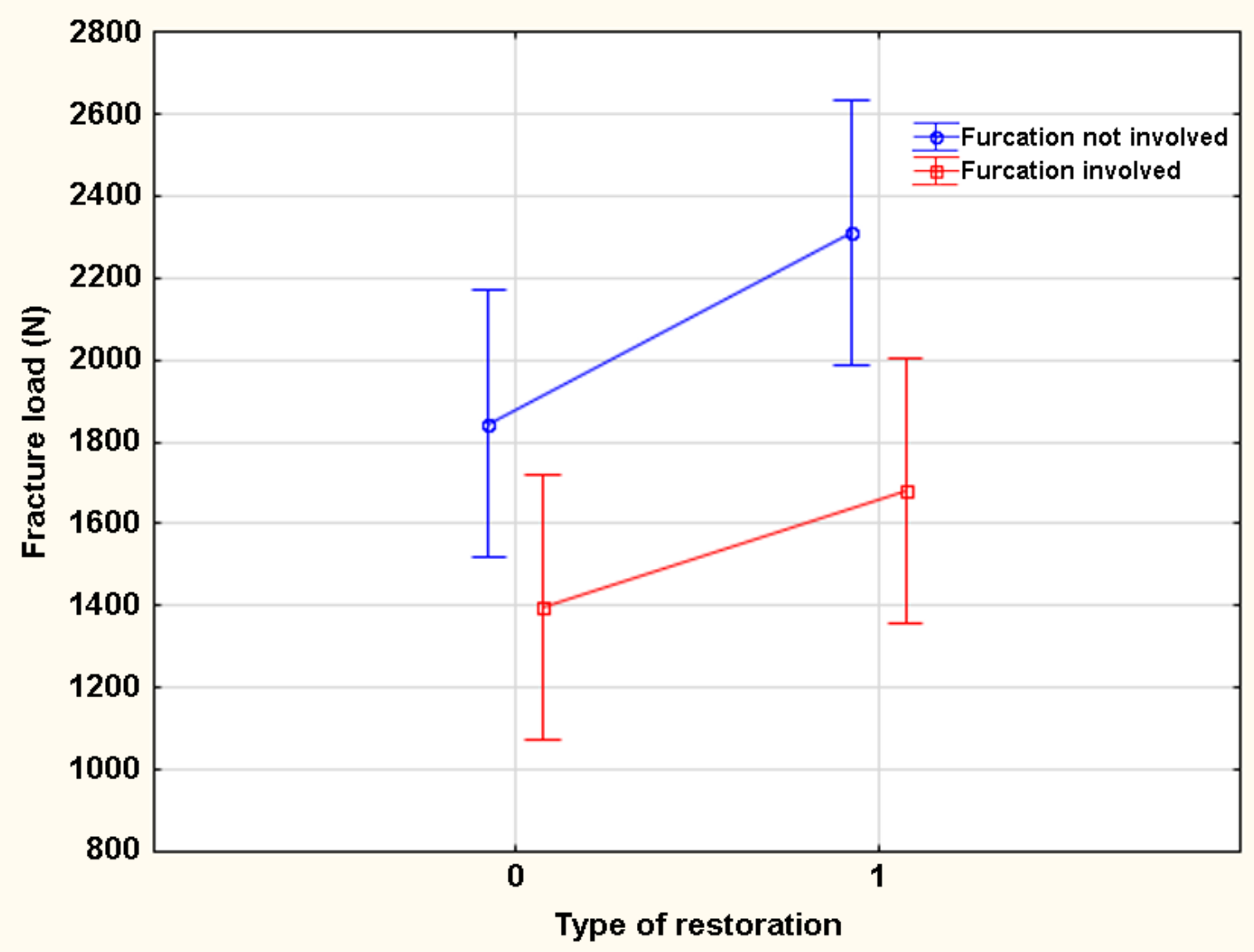

Figure 12. Differences in fracture resistance across the various conditions based on the factorial ANOVA. X: type of restoration (0: filling, 1: overlay); Y: fracture resistance; Red: compromised periodontium (Type I furcation involvement); Blue: uncompromised periodontium (no furcation involvement). Values shown as mean $\pm 95 \% \mathrm{CI}$.

\begin{tabular}{|c|c|c|c|}
\hline Bone level & N & Mean (Newtons) & SD \\
\hline Uncompromised & 30 & 2078.27 & 804.32 \\
\hline Compromised & 30 & 1540.03 & 430.54 \\
\hline
\end{tabular}

Table 5. Descriptive statistics of fracture resistance with only the type of restoration taken into consideration.

\begin{tabular}{|c|c|c|c|}
\hline Restoration type & $\mathbf{N}$ & Mean (Newtons) & SD \\
\hline Direct filling & 30 & 1621.13 & 575.78 \\
\hline Indirect overlay & 30 & 1997.17 & 759.93 \\
\hline
\end{tabular}

Table 6. Descriptive statistics of fracture resistance with only the type of restoration taken into consideration 


\section{Discussion}

Resective therapy has been utilized in the treatment of furcation defects for over a hundred years. In our study, only maxillary first molars were root-amputated and used for mechanical testing. In a retrospective study of patients with chronic or aggressive periodontal disease, maxillary molars were more frequently diagnosed with furcation lesions than mandibular molars (72\% versus 50\%) (36). This was confirmed by the findings of Svärdström et al., showing that about $50 \%$ of maxillary molars of patients with varying degrees of periodontal disease had at least one deeply involved furcation site (37), whereas this number was approximately $90 \%$ in patients diagnosed with generalized advanced periodontitis (38).

In our study design, the MB root of maxillary first molars was amputated. This choice had multiple reasons. Of all the canals in the maxillary first molar, the MB second canal can be the most difficult to find and treat in a clinical situation (39). According to Degerness et al., 20\% of maxillary first molars had one canal, $79.8 \%$ had two canals and $1.1 \%$ had three canals in the MB root (40). This is in line with the findings of Cleghorn et al., showing that maxillary first molars contained a MB second canal in more than $50 \%$ of cases in both in vivo and in vitro studies (39). As shown by Wolcott et al., failure to detect and treat the MB second canal system would result in a decreased long-term prognosis (41), thus finding and being able to treat the MB second canal is of high importance. Nascimento et al. showed that the most frequent technical error in the endodontic treatment of maxillary molars was the non-obturation of the MB second canal (42). Regarding the apical part of the canals, the presence of an apical delta in the MB root is much more likely than those in the distobuccal or palatal root (43), which, as being difficult to clean, might compromise treatment outcomes. If found and treated, and since MB second canals are smaller than main canals, and are often obliterated and curved (44), more obstacles will arise in retreatment cases during their negotiation. Also, the MB root has a pronounced concavity facing the internal aspect of the furcation, making access for plaque removal difficult (45). Concerning future maintenance, in case the MB root was removed, a furcation facing anteriorly partly remains, enhancing access for interproximal brushing of the tooth (45). Due to the multiple reasons mentioned above and based upon the clinical experience of the authors regarding possible indications for root amputation, the MB root was amputated in or studies. 
In both of our studies, different bone levels (no furcation involvement versus furcation involvement) were simulated to investigate their potential effect on fracture resistance of the tooth-restoration complex in root-amputated teeth. As pointed out by Nieri et al., the amount of bone supporting the remaining roots at the time of surgery affected the survival rate of molars with periodontal problems, and the initial bone level was found to be the most significant prognostic factor (46). The success after root amputation has been documented in many scientific papers. Park et al. found that molars with bone support $>50 \%$ around the remaining roots at the time of root resection showed significantly higher survival rates compared to molars with $<50 \%$ bone support (22). In our studies, the simulation of different bone levels seemed to have an impact on the mechanical resistance of root-amputated maxillary teeth. According to our findings in both studies, teeth with sound periodontal support (no furcation involvement; Group 1 in the pilot study, and Groups 3 and 5 in the second study) seemed to show a tendency of higher fracture resistance than teeth with simulated furcation involvement (Group 2 in the pilot study, and Group 4 and 6 in the second study). This was confirmed by the factorial ANOVA showing that the state of the periodontium around root-amputated teeth is a significant factor on its own $(p=0.002)$. Moreover, Group 3 showed a statistically significant difference in terms of fracture resistance compared to Group $4(p=0.038)$ and $6(p=0.0011)$. The reason behind these findings is manifold. Partly, this could be because of the impaired crown-to-root ratio in periodontally compromised cases that leads to inferior results. As pointed out by Daguci et al., it is highly important that the crown-to-root ratio needs to be correct in order to allow sufficient retention for the future restoration (47). Also, the type of coronal restoration could have influenced the outcome (see later).

The failure rate of root-amputated molar teeth varies between $25 \%(22)$ and $38 \%(48,49)$. The failure is mostly mechanical (i.e. fracture), but it can also be the reoccurrence of a periapical lesion in case the patient remains periodontally compromised. Ruiz et al. showed that the risk of developing apical periodontitis in endodontically treated teeth is 5.19 times higher for patients with periodontal diseases compared to patients without periodontal diseases (50). To the best of our knowledge, no one has tested the fracture resistance of root-amputated molar teeth with simulating different bone level conditions before.

Regarding the possible influence of coronal restorations, in the second study we tested Class I and Class II MOD cavities, as literature considers these the most relevant concerning rootamputated molar teeth. According to previous studies, Class I cavities in root canal treated molars can be safely restored with direct composite restorations (51-53). Although root canal- 
treated teeth are weakened by the access cavity preparation process $(54,55)$, the presence of both marginal ridges is still protecting and "splinting" the occlusal tooth structure (53), leading to a moderate $20 \%$ reduction of cuspal stiffness (56). Meanwhile, a standardized MOD cavity preparation in maxillary premolar teeth was shown to result in an average loss of $63 \%$ in relative cuspal stiffness (57), which is related principally to the loss of marginal ridge integrity (58). This leads to an approximately $54 \%$ reduction in fracture strength $(59,60)$. Furthermore, in root canal treated MOD cavities, due to the extreme depth of the cavity and the lost protection of the marginal ridges, the cantilever arm increases on the remaining walls, leading to reduced fracture resistance to an extent, which cannot be reinforced with a direct composite filling (60). This is in accordance with the laboratory findings of Eapen et al. (61), Kemaloglu et al. (62) and Forster et al. (60). Even the usage of modern fibre-reinforced materials cannot fully reinforce MOD cavities in root canal treated teeth without cuspal coverage (63). As stated by Seow et al., the depth of the preparation is the most critical factor for the prepared tooth in predisposing the risk factors of fracture (64). Extracoronal strengthening by cuspal coverage is generally advisable in case of root canal treated posterior teeth (65). Traditionally, full coverage crowns have been used, but adhesively placed restorations with total cuspal coverage (overlays) have been proposed lately as a more conservative alternative (66). In our second study, teeth restored with cuspal coverage restorations (Group 3 and 4) showed slightly higher fracture resistance compared to the groups receiving direct filling (Group 5 and 6) at the same level of simulated periodontal support, though the difference was not statistically significant. According to the factorial ANOVA, both evaluated factors, namely the bone level around the root amputated tooth $(p=0.002)$ and the type of coronal restoration $(p=0.023)$ are significant factors, but it seems there is no correlation between the effects $(p=0.58)$. The bone level together with an indirect cuspal coverage restoration (overlay) seemed to have a real impact on fracture resistance of root-amputated molar teeth, since Group 3 was significantly stronger than teeth with reduced periodontal support (Group 4 and 6), irrespective of their coronal restoration. The effect of periodontal integrity appears to be greater according to the factorial ANOVA also, but the broad distribution of the data does not allow a firm conclusion regarding that. Though increasing the amount of simulated periodontal support seemed to increase fracture resistance, it could not result in a significant difference in fracture resistance when comparing teeth restored with direct filling (Group 5) with the group of simulated furcation involvement (Group 4 and 6). Therefore, within the limitations of this study, it appears that cuspal coverage could lead to better fracture resistance values in root-amputated upper molars, clearly when accompanied with a normal bone support. 
Traditionally, a considerable proportion of root canal treated teeth would be restored in a way that involved the use of a post, in the belief that they were reinforced (67); however, as it was pointed out by several studies, fibre-reinforced composite posts fail to reinforce root canal treated molar teeth $(33,68)$. We used SFRC in all study groups to rebuild the missing dentine. SFRC is intended to be used in high stress bearing areas in both vital and non-vital teeth, especially in molars $(69,70)$. As the fibres incorporated into the SFRC have a length equal to or greater than the critical fibre length $(0.5-1.6 \mathrm{~mm})(71)$, it can act as a stress-absorbing dentine-replacing material (69). In our study design, the use of SFRC in general could not shift the fracture pattern toward predominantly favorable result, contrary to the previous findings of Fráter et al. (72). In our study, it was only in Group 5 that the fracture pattern was predominantly favorable. We could only hypothesize that this might be due to the combination of conservative direct restoration, the use of SFRC as a core material and a favorable bone level. In the rest of the groups, there was a shift toward unfavorable fractures. The explanation for this might be that all the teeth tested were root-amputated, which not only weakened the structure, but most likely altered the stress distribution pattern as well. Group 5 also contained root-amputated teeth, but in this group, the simulated bone level was favorable, and the coronal structure was more preserved, which could possibly account for a dominantly favorable fracture pattern.

In case of root-amputated maxillary molars, the possible role of simulated bone level and later the type of coronal restoration were tested under in vitro conditions using extracted teeth, which holds some possible limitations. One disadvantage when using human teeth for testing is the large variation among individual teeth (e.g. in mechanical and physical properties), and existing microcracks in the dentine may not always be seen before testing. In general, this may lead to large standard deviations. Despite the mentioned shortcomings, the use of natural human teeth is a reliable method for fracture testing and still represent the first choice for in vitro tests (73). When utilizing human teeth, the establishment of strict exclusion and inclusion criteria is mandatory. Within our study designs, both the coronal part and the roots of maxillary molars were carefully standardized. Teeth should be used within 2-6 months after extraction and they must be kept in specific solutions before use. This was taken into account in our studies.

In our performed studies, fracture resistance was measured in a static load-to-fracture setup using a universal testing machine. This is a known limitation of these investigations, since a static load-to-fracture test is used to determine maximal fracture resistance instead of applying cyclic loading. Stress applied to teeth and dental restorations is generally low and repetitive rather than being isolated and impactive in nature (63). However, because of a linear 
relationship between fatigue and static loading, the compressive static test also gives valuable information concerning fracture behaviour and load-bearing capacity (74). According to Taha et al., „In experimental studies, fracture resistance to static loading has been used as a measure of the effect of cavity preparation and/or restoration on tooth strength. Although the fracture load is typically much higher than functional occlusal loads, it is still a valid method for comparing restorative materials and different cavity designs." (75). Also, as stated by Le BellRönnlöf et al., static loading is usually the first step in the evaluation process of novel dental materials and related techniques, and is commonly used in order to obtain basic knowledge regarding fracture behaviour and load capacity of a restored tooth (76). There are several factors that may interfere with the measured fracture resistance, such as the differences between specimens, tooth embedding method, type and direction of load application, crosshead speed and simulation of thermal or mechanical fatiguing (77). During this test, intraoral conditions should be mimicked as much as possible. During the embedding of samples, two important elements should be emphasized: simulating the periodontal ligaments and simulating the bone level around the roots. In order to best mimic the elastic property of the periodontal ligaments, which normally connects the roots to the bone in a healthy clinical situation, the root part of the samples is covered with a layer of liquid latex separating material prior to embedding $(72,78)$. This is highly important as the ligaments provide a $0.05 \mathrm{~mm}$ movement for the teeth in the bony socket, thus it absorbs stress to a certain amount before transferring it to the bone. This is also visible in mechanical testing, if the latex is applied to the roots of the specimen. Although some studies do not use any separating agent on the root surfaces before embedding them, most studies highlight the lack of periodontal ligament simulation as a limitation of the study design with regard to their clinical relevance (59). During the embedding procedure, teeth are embedded in methacrylate resin, usually $2 \mathrm{~mm}$ apical from the CEJ to simulate the bone level. This represents a healthy situation regarding the amount of bone supporting the tooth. To the best of our knowledge, only our studies examined the effect of altered bone level on the fracture resistance of root-amputated molar teeth $(79,80)$. Once the samples are embedded, they need to be positioned under the rounded cylindrical bar delivering the loading, according to the type of tooth to be tested. In molar teeth, the bar is positioned at the centre of the occlusal surface of the tooth crown between the buccal and oral cusps. This way, a tripod contact is created by simultaneous and equal contact of the bar to the mesiobuccal, distobuccal and palatinal cusps, while the tooth is loaded from a vertical direction parallel to the long axis of the tooth. The bar delivering the loading is usually a rounded, 6-mm-diameter stainless-steel ball-shaped stylus $(31,32)$. Some research groups were trying to incorporate a more realistic relationship and 
contact with the opposing dentition into their mechanical studies. With this intent, Soares et al. was using a 6-7-mm-diameter composite resin sphere as a loading tip (81). As composite shows similar wear to human enamel, the utilization of such a sphere for loading could be beneficial, but rather in cases when dynamic loading is applied rather than static load-to-fracture cases.

We would like to emphasize that apart from the high level of standardization, another strength of our study design is that the treated teeth were embedded together with one neighbouring tooth on both sides to form tight interproximal contacts. Creating a tight interproximal contact with neighbouring teeth or even splinting them together is important in case of root-amputated teeth. The important role of interproximal contacts was demonstrated by Krug et al. when analysing the fracture resistance of root canal treated premolars (82). The authors find this a key element in the study design, as in clinical conditions, root-amputated teeth could not be left without tight contact with adjacent teeth or without splinting them to the neighbouring one.

Load-to-fracture tests resemble a possible traumatic event or biting on a foreign object or just the condition potentially present in a bruxing patient's mouth. It seems that high forces will continue to rise with the high prevalence of temporomandibular disorders leading to bruxism in modern Western societies (83). As pointed out by Deliperi et al., during the lifetime of a tooth, a wide range of overload events may happen, including those from bruxism, trauma (high extrinsic loads), or from dynamic loading (intrinsic chewing strokes in a small area due to a hard foreign body such as a stone or seed) (84). Therefore, we would like to point out that in our opinion, static loading could even be more relevant in this specific setting (i.e. rootamputated teeth with or without furcation involvement), as these teeth are more likely to fracture due to trauma or biting on a foreign object than other, non-amputated teeth. Still, this is a methodological limitation, and thus the proposed techniques and situations should be tested with cyclic, dynamic loading as well. 


\section{Summary}

The studies described in the thesis sought to evaluate how the condition of the periodontal support and the type of coronal restoration can influence the fracture resistance and the fracture pattern of root-amputated maxillary molar teeth under in vitro conditions. Within the limitations of this study, both the remaining bone level after root amputation and the type of restoration seems to have significant importance regarding the fracture resistance of root-amputated maxillary molar teeth. It seems that the most favorable combination regarding fracture resistance occurs when root-amputated maxillary molars have healthy, intact periodontium and the tooth has been restored with a cuspal coverage overlay. Although in our study the combination of sound periodontal support and overlay restoration resulted in the highest fracture resistance, this was not accompanied by dominantly favorable fracture pattern. Dominantly favorable fracture pattern could only be seen in case of the combination of sound periodontal support together with the less invasive direct filling. As in many studies and also based upon clinical findings, high fracture resistance and favorable fracture pattern does not necessarily go together. In the authors opinion, contrary to most of the restorative procedures where favorable fracture pattern is the most important thing, as root-amputated teeth are more likely to fail due to sudden masticatory trauma, higher fracture resistance could be a desired feature even on the cost of irreparable fracture pattern in these specific cases. 


\section{Acknowledgements}

Herewith I would like to express my gratitude to my supervisor Dr. Márk Fráter for his professional guidance. His high level competence such as his unbelievable motivation had a great impact on me. Without him I wouldn't have been able to perform my scientific work. I am especially thankful to Dr. Balázs P. Szabò who carried out the mechanical testing of my research. His practical knowledge in this area significantly enhanced the process of the work. My respect and thanks to Dr. Gábor Braunitzer who had turned the results of our scientific research into figures.

I am grateful to Dr. Gabriella Eördegh Nagyné for her professional and friendly support. Special thanks to Dr. Veronika T. Szabó for the enormous effort she made during the preparation of the experiments and also for her personal presence.

I would like to acknowledge the help of Dr. Zoltán Baráth in the success of my articles. Last but not least a great appreciation to Dr. Botond Dávid Hangyási who motivated me in choosing periodontology as my main scientific field of interest. 


\section{References}

1. Eke PI, Wei L, Borgnakke WS, Thornton-Evans G, Zhang X, Lu H, et al. Periodontitis prevalence in adults $>/=65$ years of age, in the USA. Periodontol 2000. Denmark. 2016;72(1):76-95.

2. Eke PI, Dye BA, Wei L, Slade GD, Thornton-Evans GO, Borgnakke WS, Taylor GW, Page RC, Beck JD, Genco RJ. Update on Prevalence of Periodontitis in Adults in the United States: NHANES 2009 to 2012. J Periodontol. 2015 May;86(5):611-22.

3. Albandar JM. A 6-year study on the pattern of periodontal disease progression. J Clin Periodontol. United States. 1990 Aug;17(7 Pt 1):467-71.

4. Albandar JM, Rise J, Gjermo P, Johansen JR. Radiographic quantification of alveolar bone level changes. A 2-year longitudinal study in man. J Clin Periodontol. United States; 1986 Mar;13(3):195-200.

5. American Academy of Periodontology . Glossary of Periodontal Terms. 4th ed. American Academy of Periodontology; Chicago, LA, USA: 2001.

6. Lindhe J, Socransky SS, Nyman S, Haffajee A, Westfelt E. "Critical probing depths" in periodontal therapy. J Clin Periodontol. 1982 Jul;9(4):323-36.

7. Heitz-Mayfield LJ, Lang NP. Surgical and nonsurgical periodontal therapy. Learned and unlearned concepts. Periodontol 2000. 2013 Jun;62(1):218-31.

8. Kaldahl WB, Kalkwarf KL, Patil KD, Molvar MP, Dyer JK. Long-term evaluation of periodontal therapy: I. Response to 4 therapeutic modalities. J Periodontol. 1996 Feb;67(2):93102.

9. Hägi TT, Laugisch O, Ivanovic A, Sculean A. Regenerative periodontal therapy. Quintessence Int. 2014 Mar;45(3):185-92.

10. Löst, Claus: Hemisektion und Wurzelamputation Löst / Claus Löst. -München ;Wien : Hanser, 1985.

11. DeSanctis M, Murphy KG. The role of resective periodontal surgery in the treatment of furcation defects. Periodontol. 2000;22:154-68. Review.

12. Baima RF. Considerations for furcation treatment. Part III: restorative therapy. J Prosthet Dent. 1987;58(2):145-7. 
13. Sousa V, Mardas N, Farias B, Petrie A, Needleman I, Spratt D, Donos N. A systematic review of implant outcomes in treated periodontitis patients. Clin Oral Implants Res. 2016 Jul;27(7):787-844.

14. Mokbel N, Kassir AR, Naaman N, Megarbane JM. Root Resection and Hemisection Revisited. Part I: A Systematic Review. Int J Periodontics Restorative Dent. 2019 Jan/Feb;39(1):e11-e31.

15. Megarbane JM, Kassir AR, Mokbel N, Naaman N. Root Resection and Hemisection Revisited. Part II: A Retrospective Analysis of 195 Treated Patients with Up to 40 Years of Follow-up. Int J Periodontics Restorative Dent. 2018 Nov/Dec;38(6):783-9.

16. Mani A, James R, Mani S. Classifications for Furcation Involvement. Galore International Journal of Health Sciences and Research Vol.3; Issue: 1; Jan.-March 2018.

17. Hamp SE, Nyman S, Lindhe J. Periodontal treatment of multirooted teeth. Results after 5 years. J Clin Periodontol. 1975 Aug;2(3):126-35.

18. Ramfjord, S. P. \& Ash, M. M. Jr. (1979) Periodontology and periodontics. Philadelphia:WB Saunders.

19. Tarnow D, Fletcher P. Classification of the vertical component of furcation involvement. J Periodontol. 1984 May;55(5):283-4.

20. Walter C, Weiger R, Zitzmann NU. Periodontal surgery in furcation-involved maxillary molars revisited--an introduction of guidelines for comprehensive treatment. Clin Oral Investig. 2011 Feb;15(1):9-20.

21. Miron RJ, Sculean A, Cochran DL, Froum S, Zucchelli G, Nemcovsky C, Donos N, Lyngstadaas SP, Deschner J, Dard M, Stavropoulos A, Zhang Y, Trombelli L, Kasaj A, Shirakata Y, Cortellini P, Tonetti M, Rasperini G, Jepsen S, Bosshardt DD. Twenty years of enamel matrix derivative: the past, the present and the future. J Clin Periodontol. 2016 Aug;43(8):668-83.

22. Park SY, Shin SY, Yang SM, Kye SB. Factors influencing the outcome of root-resection therapy in molars: a 10-year retrospective study. J Periodontol. 2009 Jan;80(1):32-40.

23. Farrar JN. Radical and Heroic Treatment of Alveolar Abscess by Amputation of Roots of Teeth.Dent Cosmos 1884;26:135-9. 
24. Hamp SE, Ravald N, Teiwik A, Lundstrom A. Modes of furcation treatment in a long-term prospective study. J Periodontol 1992;11:11-23.

25. Horwitz J, Machtei EE, Reitmeir P, Holle R, Kim TS, Eickholz P. Radiographic parameters as prognostic indicators for healing of class II furcation defects. J Clin Periodontol. 2004 Feb;31(2):105-11.

26. Langer B, Stein SD, Wagenberg B. An evaluation of root resections. A ten-year study. J Periodontol. 1981 Dec;52(12):719-22.

27. Klavan B. Clinical observations following root amputation in maxillary molar teeth. J Periodontol 1975;46:1-5.

28. Carnevale G, Pontoriero R, di Febo G. Long-term effects of root-resective therapy in furcation-involved molars. A 10-year longitudinal study. J Clin Periodontol. 1998 Mar;25(3):209-14.

29. Lee KL, Corbet EF, Leung WK. Survival of molar teeth after resective periodontal therapy-a retrospective study. J Clin Periodontol. 2012 Sep;39(9):850-60.

30. Cara RR, Fleming GJ, Palin WM, Walmsley AD, Burke FJ. Cuspal deflection and microleakage in premolar teeth restored with resin-based composites with and without an intermediary flowable layer. J Dent. 2007;35(6):482-9.

31. Soares CJ, Martins LR, Pfeifer JM, Giannini M. Fracture resistance of teeth restored with indirect-composite and ceramic inlay systems. Quintessence Int. 2004;35(4):281-6.

32. Cobankara FK, Unlu N, Cetin AR, Ozkan HB. The effect of different restoration techniques on the fracture resistance of endodontically-treated molars. Oper Dent. 2008;33(5):526-33.

33. Scotti N, Coero Borga FA, Alovisi M, Rota R, Pasqualini D, Berutti E. Is fracture resistance of endodontically treated mandibular molars restored with indirect onlay composite restorations influenced by fiber post insertion? J Dent. 2012;40:814-20.

34. Plotino G, Grande NM, Isufi A, Ioppolo P, Pedulla E, Bedini R, Gambarini G, Testarelli L. Fracture strength of Endodontically treated teeth with different access cavity designs. J Endod. 2017;43(6):995-1000.

35. Patel S, Rhodes J. A practical guide to endodontic access cavity preparation in molar teeth. Br Dent J. 2007;203(3):133-40. 
36. Dannewitz B, Krieger JK, Hüsing J, Eickholz P. Loss of molars in periodontally treated patients: a retrospective analysis five years or more after active periodontal treatment. J Clin Periodontol. 2006;33(1):53-61.

37. Svärdström G, Wennström JL. Prevalence of furcation involvements in patients referred for periodontal treatment. J Clin Periodontol. 1996;23(12):1093-9.

38. Ross IF, Thompson RH Jr. Furcation involvement in maxillary and mandibular molars. J Periodontol. 1980;51(8):450-4.

39. Cleghorn BM, Christie WH, Dong CC. Root and root canal morphology of the human permanent maxillary first molar: a literature review. J Endod. 2006;32(9):813-21.

40. Degerness RA, Bowles WR. Dimension, anatomy and morphology of the mesiobuccal root canal system in maxillary molars. J Endod. 2010;36(6):985-9.

41. Wolcott J, Ishley D, Kennedy W, Johnson S, Minnich S. Clinical investigation of second mesiobuccal canals in endodontically treated and retreated maxillary molars. J Endod. 2002;28(6):477-9.

42. Nascimento EHL, Gaêta-Araujo H, Andrade MFS, Freitas DQ. Prevalence of technical errors and periapical lesions in a sample of endodontically treated teeth: a CBCT analysis. Clin Oral Investig. 2018;22(7):2495-503.

43. Gao X, Tay FR, Gutmann JL, Fan W, Xu T, Fan B. Micro-CT evaluation of apical delta morphologies in human teeth. Sci Rep. 2016;6:36501.

44. Zuolo ML, Carvalho MC, De-Deus G. Negotiability of second Mesiobuccal canals in maxillary molars using a reciprocating system. J Endod. 2015;41(11):1913-7.

45. Schmitt SM, Brown FH. Management of root-amputated maxillary molar teeth: periodontal and prosthetic considerations. J Prosthet Dent. 1989;61(6):648-52.

46. Nieri M, Muzzi L, Cattabriga M, Rotundo R, Cairo F, Pini Prato GP. The prognostic value of several periodontal factors measured as radiographic bone level variation: a 10-year retrospective multilevel analysis of treated and maintained periodontal patients. J Periodontol. 2002;73(12):1485-93.

47. Dăguci C, Dăguci L, Bătăiosu M, Popescu MR, Bunget A, Margarit R, Andrei OC, Dumitrache A, Vasile N, Sfeatcu R. Changing the root morphology in a case of periodontal impairment at a maxillary molar used as a sustaining tooth. Romanian J Morphol Embryol. 2014;55(3):957-60.

48. Green EN. Hemisection and root amputation. J Am Dent Assoc. 1986;112(4):511-8. Review. 
49. Blomlöf L, Jansson L, Appelgren R, Ehnevid H, Lindskog S. Prognosis and mortality of root-resected molars. Int J Periodontics Restorative Dent. 1997;17(2):190-201.

50. Ruiz XF, Duran-Sindreu F, Shemesh H, García Font M, Vallés M, Roig Cayón M, Olivieri JG . Development of periapical lesions in endodontically treated teeth with and without periodontal involvement: a retrospective cohort study. J Endod. 2017;43(8):1246-9.

51. Frankenberger R, Zeilinger I, Krech M, Mörig G, Naumann M, Braun A, Kramer N, Roggendorf MJ. Stability of endodontically treated teeth with differently invasive restorations: adhesive vs. nonadhesive cusp stabilization. Dent Mater. 2015;31(11):1312-20.

52. Rocca GT, Krejci I. Crown and post-free adhesive restorations for endodontically treated posterior teeth: from direct composite to endocrowns. Eur J Esthet Dent. 2013;8(2):156-79.

53. Daher R, Feilzer AJ, Krejci I. Novel non-invasive reinforcement of MOD cavities on endodontically treated teeth. J Dent. 2016;54:77-85.

54. Dietschi D, Duc O, Krejci I, Sadan A. Biomechanical considerations for the restoration of endodontically treated teeth: a systematic review of the literature--part 1. Composition and micro- and macrostructure alterations. Quintessence Int. 2007;38(9):733-43.

55. Al-Omiri MK, Mahmoud AA, Rayyan MR, Abu-Hammad O. Fracture resistance of teeth restored with post-retained restorations: an overview. J Endod. 2010;36(9):1439-49.

56. Tay FR, Pashley DH. Monoblocks in root canals: a hypothetical or a tangible goal. J Endod. 2007;33(4):391-8.

57. El-Helali R, Dowling AH, McGinley EL, Dunkan HF, Fleming GJ. Influence of resin-based composite restoration technique and endodontic access on cuspal deflection and cervical microleakage scores. J Dent. 2013;41(3):216-22.

58. Reeh ES, Douglas WH, Messer HH. Stiffness of endodontically-treated teeth related to restoration technique. J Dent Res. 1989;68(11):1540-4.

59. Hannig C, Westphal C, Becker K, Attin T. Fracture resistance of endodontically treated maxillary premolars restored with CAD/CAM ceramic inlays. J Prosthet Dent. 2005;94(4):3429.

60. Forster A, Braunitzer G, Tóth M, Szabó PB, Fráter M. In vitro fracture resistance of adhesively restored molar teeth with different MOD cavity dimensions. J Prosthodont. 2019;28(1):e325-31.

61. Eapen AM, Amirtharaj LV, Sanjeev K, Mahalaxmi S. Fracture resistance of endodontically treated teeth restored with 2 different fiber-reinforced composite and 2 conventional composite resin core buildup materials: an in vitro study. J Endod. 2017;43(9):1499-504. 
62. Kemaloglu H, Emin Kaval M, Turkun M, Micoogullari Kurt S. Effect of novel restoration techniques on the fracture resistance of teeth treated endodontically: an in vitro study. Dent Mater J. 2015;34(5):618-22.

63. Fráter M, Lassila L, Braunitzer G, Vallittu PK, Garoushi S. Fracture resistance and marginal gap formation of post-core restorations: influence of different fiber-reinforced composites. Clin Oral Investig. 2020 Jan;24(1):265-76.

64. Seow LL, Toh CG, Wilson NH. Strain measurements and fracture resistance of endodontically treated premolars restored with all-ceramic restorations. $\mathrm{J}$ Dent. 2015;43(1):126-32.

65. Magne P, Knezevic A. Thickness of CAD-CAM composite resin overlays influences fatigue resistance of endodontically treated premolars. Dent Mater. 2009;25(10):1264-8.

66. Magne P. Composite resins and bonded porcelain: the postamalgam era? J Calif Dent Assoc. 2006;34(2):135-47 Review.

67. Kirzioğlu Z, Ertürk MS. Reconstruction and recovery of hemisectioned teeth using direct fiber-reinforced composite resin: case report. J Dent Child (Chic). 2008;75(1):95-8.

68. Magne P, Carvalho AO, Bruzi G, Anderson RE, Maia HP, Giannini M. Influence of noferrule and no-post buildup design on the fatigue resistance of endodontically treated molars restored with resin nanoceramic CAD/CAM crowns. Oper Dent. 2014;39(6):595-602.

69. Garoushi S, Gargoum A, Vallittu PK, Lassila L. Short fiber-reinforced composite restorations: a review of the current literature. J Investig Clin Dent. 2018;9(3):e12330.

70. Garoushi S, Mangoush E, Vallittu M, Lassila L. Short fiber reinforced composite: a new alternative for direct onlay restorations. Open Dent J. 2013;7:181-5.

71. Vallittu PK. High-aspect ratio fillers: Fiber-reinforced composites and their anisotropic properties. Dent Mater. 2015;31:1-7.

72. Fráter M, Forster A, Keresztúri M, Braunitzer G, Nagy K, In vitro fracture resistance of molar teeth restored with a short fibre-reinforced composite material. J Dent. 2014;42(9):114350.

73. Alshahrani FA, Yilmaz B, Seidt JD, McGlumphy EA, Brantley WA. A load-to-fracture and strain analysis of monolithic zirconia cantilevered frameworks. J Prosthet Dent. 2017 Dec;118(6):752-8.

74. Garoushi S, Lassila LV, Tezvergil A, Vallittu PK. Static and fatigue compression test for particulate filler composite resin with fiber-reinforced composite substructure. Dent Mater. 2007 Jan;23(1):17-23. 
75. Taha NA, Palamara JE, Messer HH. Fracture strength and fracture patterns of root filled teeth restored with direct resin restorations. J Dent. 2011 Aug;39(8):527-35.

76. Le Bell-Rönnlöf AM, Lassila LV, Kangasniemi I, Vallittu PK. Load-bearing capacity of human incisor restored with various fiber-reinforced composite posts. Dent Mater. 2011;27(6):e107-15.

77. Plotino G, Buono L, Grande NM, Lamorgese V, Somma F. Fracture resistance of endodontically treated molars restored with extensive composite resin restorations. J Prosthet Dent. 2008 Mar;99(3):225-32.

78. Szabó PB, Sáry T, Szabó B. The key elements of conducting load-to-fracture mechanical testing on restoration-tooth units in restorative dentistry. Analecta Technika Szegedinensia 2019;13(2): 59-64. DOI: 10.14232/analecta.2019.2.59-64

79. Szabó B, Eördegh G, Szabó PB, Fráter M. In vitro fracture resistance of root amputated molar teeth restored with overlay: a pilot study. Fogorv Szle. 2017:111-116.

80. Szabó B, Garoushi S, Braunitzer G, Szabó P B, Baráth Z, Fráter M. Fracture behavior of root-amputated teeth at different amount of periodontal support - a preliminary in vitro study. BMC Oral Health. 2019 Nov 27;19(1):261.

81. Soares LM, Razaghy M, Magne P. Optimization of large MOD restorations: Composite resin inlays vs. short fiber-reinforced direct restorations. Dent Mater. 2018 Apr;34(4):587-97. 82. Krug KP, Otter SE, Knauber AW, Erdelt KJ, Nothdurft FP. Influence of proximal contacts and FRC posts on the fracture behavior of premolars with class II composite restorations: an in-vitro study. Dent Mater J. 2013;32(6):952-8.

83. Volom A, Fráter M. Transmural fiber reinforcement in order to restore the fracture resistance of large MOD cavities - a technical report. Fogorv Szle. 2019 Sept;112(3):82-6.

84. Deliperi S, Alleman D, Rudo D. Stress-reduced Direct Composites for the Restoration of Structurally Compromised Teeth: Fiber Design According to the "Wallpapering" Technique. Oper Dent. 2017 May/June;42(3):233-243. 


\section{List of abbreviations}

MOD - mesio-occluso-distal

BPW - bucco-palatinal width

CEJ - cemento-enamel

SFRC - short fiber-reinforced composite

MB - mesio-buccal

TEC - traditional endodontic access 


\section{Appendix}

Copy of the publications providing the basis of the thesis. 